Advances in Geosciences, 6, 63-67, 2006

SRef-ID: $1680-7359 /$ adgeo/2006-6-63

European Geosciences Union

(c) 2006 Author(s). This work is licensed

under a Creative Commons License.

\title{
Changes in the diet of hake associated with EI Niño 1997-1998 in the northern Humboldt Current ecosystem
}

\author{
J. Tam ${ }^{1}$, S. Purca ${ }^{1}$, L. O. Duarte ${ }^{2}$, V. Blaskovic ${ }^{3}$, and P. Espinoza ${ }^{3}$ \\ ${ }^{1}$ Research Center for Oceanographic and Biological Fishery Modelling (CIMOBP), Peruvian Marine Research Institute \\ (IMARPE), Lima, Peru \\ ${ }^{2}$ Laboratorio de Investigaciones Pesqueras Tropicales, Universidad del Magdalena, Santa Marta, Colombia \\ ${ }^{3}$ Trophic Ecology Area, Peruvian Marine Research Institute (IMARPE), Lima, Peru
}

Received: 30 June 2005 - Revised: 20 October 2005 - Accepted: 28 October 2005 - Published: 9 January 2006

\begin{abstract}
Hake (Merluccius gayi peruanus) predation plays an important role in the dynamics of the Humboldt Current ecosystem (HCE). Changes in the hake trophic habits associated with physical variability are expected to impact prey populations and to propagate through the food web. Time series (1995-2002) of (a) stomach contents of hake, (b) biomass estimations of fish prey species of hake, and (c) depth of the $15^{\circ} \mathrm{C}$ isotherm was analysed with the aim of exploring the impacts of El Niño 1997-1998 on the diet of hake. Biomass estimations of fish prey species were used to indicate resource availability, and depth of the $15^{\circ} \mathrm{C}$ isotherm to represent variability associated with the ENSO cycle in the physical environment of hake. The richness of prey species increased during the months when $15^{\circ} \mathrm{C}$ isotherm reached its deepest position, supporting the hypothesis of increased biodiversity (tropicalization) of the HCE during El Niño events. An increased variability in stomach fullness of hake was detected after 1999 which could indicate high heterogeneity in the food supply as a consequence of impacts of the warm event in the biotic community structure of the HCE, a physiological impairment of hake or an effect of the abrupt reduction in the mean total length of hake, postulated as a compensatory response to fishery pressure. Hake can be characterized as an opportunist predator according to the observed changes in its diet during 1995-2002. Overall, the diet of hake in the northern HCE exhibited transitory (e.g. increased richness of prey species in the stomach contents) and medium term (e.g. increased variability in feeding activity) responses associated with El Niño 1997-1998, which should be incorporated both in population dynamics and food web analyses.
\end{abstract}

\section{Introduction}

Hake (Merluccius gayi peruanus) is a dominant demersal fishery resource in the Humboldt Current ecosystem (HCE). It occupies a high trophic level in the ecosystem and has been subjected to strong fluctuations of the physical environment like those associated with the El Niño Southern Oscillation (ENSO) cycle (Alheit and Pitcher, 1995). Hake predation plays an important role in the dynamics of both the HCE and the eastern boundary current ecosystems (Konchina, 1983; Ware, 1992). Changes in hake trophic habits associated with physical variability are expected to impact prey populations and to propagate throughout the food web.

The displacement of warm waters from the tropical Pacific to the HCE during the El Niño events has promoted transient suitable areas for tropical species that could diversify the food supply for local predators (Arntz and Fahrbach, 1996).

The objective of this paper is to determine the susceptibility of hake population to changes in prey abundance and composition triggered by the El Niño 1997-1998 event, through the analysis of time series (1995-2002) of (a) stomach contents of hake, (b) biomass estimations of fish prey species of hake, and (c) depth of the $15^{\circ} \mathrm{C}$ isotherm. Biomass estimations of fish prey species were used to indicate resource availability, and depth of the $15^{\circ} \mathrm{C}$ isotherm to represent variability associated with the ENSO cycle in the physical environment of hake. The role of feeding changes of hake in the ecosystem is discussed.

Correspondence to: J. Tam

(jtam@imarpe.gob.pe) 


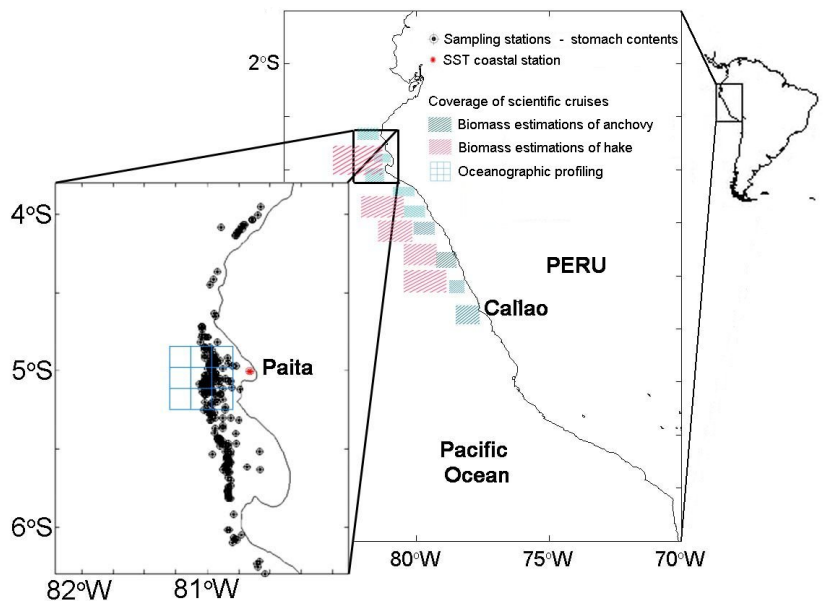

Fig. 1. Location of the sampling stations for diet analysis of hake, oceanographic coastal station and coverage of scientific cruises for biomass estimations and oceanographic profiling in the northern Humboldt Current ecosystem (HCE).

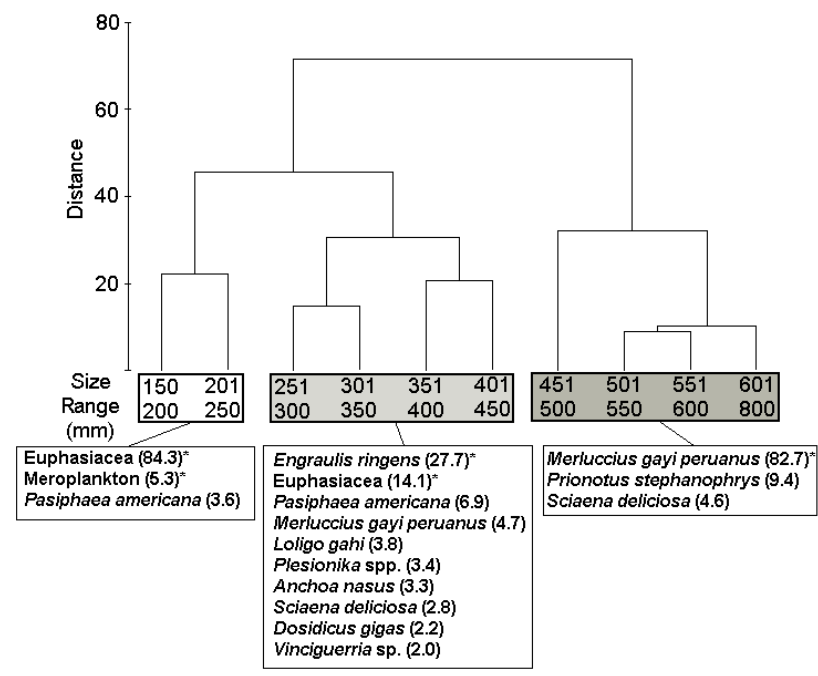

Fig. 2. Size-related groups of hake based on diet composition as derived by a cluster analysis (Euclidean distance, average grouping) in the Northern HCE. Significant differences between groups were confirmed by an ANOSIM procedure. Percentage of contribution of characteristic prey taxa to the similarity within each hake size group is indicated in brackets.

\section{Methods}

\subsection{Sources of information}

Stomach contents from commercial landings of hake between October 1995 and November 2002 of the northern HCE $\left(5^{\circ} \mathrm{S}-6^{\circ} \mathrm{S}\right.$, Fig. 1$)$ were analysed by the Trophic Ecology Laboratory at IMARPE. Biomass estimations of hake and anchovy were obtained from literature (Espino, 1999; Gutiérrez, 2000). Monthly data of sea surface temperature anomaly (SSTA) measured at a fixed oceanographic station off Paita (Fig. 1) and depth of the $15^{\circ} \mathrm{C}$ isotherm recorded
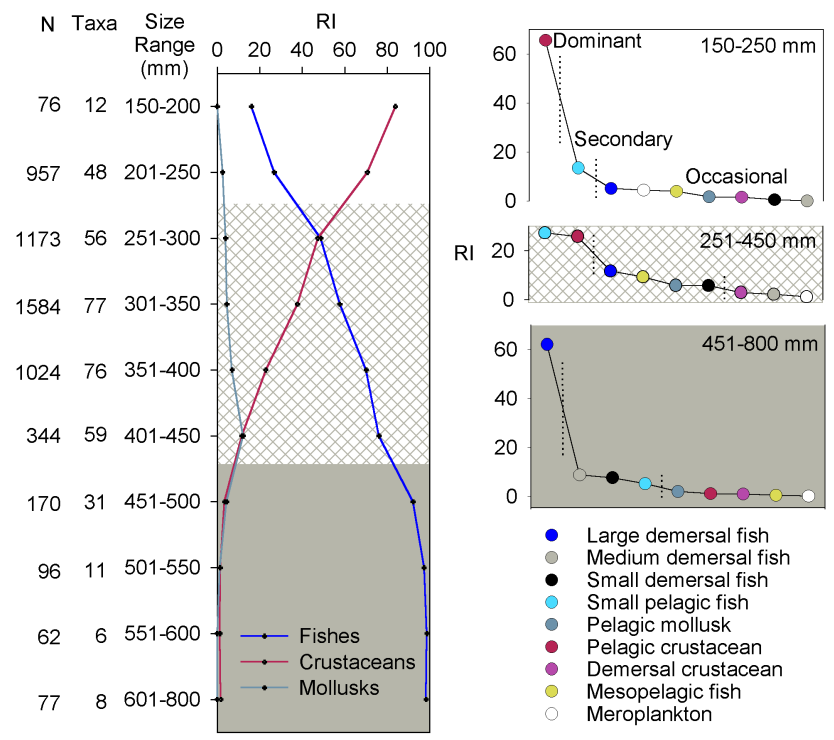

Fig. 3. Relative importance of prey categories in the diet of hake. Changes in general prey groups with size are shown in the left panel. According to discontinuities in RI values, prey categories can be characterised as dominant, secondary or occasional in the hake size groups derived from the multivariate analysis (right panels).

by scientific cruises carried out in the area were taken by the Physical Oceanography Area of IMARPE. The SSTA was standardized with a base period from 1995 to 2002.

\subsection{Diet analysis}

For each individual total length and total weight were recorded. Stomach contents were identified to the lowest possible taxonomic level. The contribution of each prey item was determined by two Relative Measures of Prey Quantity (RMPQ): gravimetric (\%W) and frequency of occurrence $(\% \mathrm{~F})$ (Hyslop, 1980). A generalised form of the Relative Importance (RI) Index (George and Haley, 1979) was computed for each prey taxon as:

$$
R I=100 \quad\left(\sum_{i=1}^{m} V_{i j} / \sum_{i=1}^{m} \sum_{j=1}^{n} V_{i j}\right)
$$

where, $V_{i j}$ is the $i$-th RMPQ of prey $j$.

In order to avoid the potential influence of size of hake as a confounding factor for temporal analyses, size-related groups were elucidated using a multivariate analysis of diet composition. Thus, the total fish sample was divided in ten length class intervals of $5 \mathrm{~cm}$ each, and groups were defined performing a cluster analysis with average grouping technique and using the euclidean distance dissimilarity between size classes. A montecarlo-based ANOSIM procedure (Clarke and Green, 1988) was used to test the null hypothesis of no differences in the diet structure between the size groups elucidated in the cluster analysis. Typifying prey items for each size group were determined by the SIMPER protocol (Clarke, 1993). For the size group with available data throughout the study period (see Results), monthly estimations of RI index, prey spectrum diversity (Hill's N1 and 


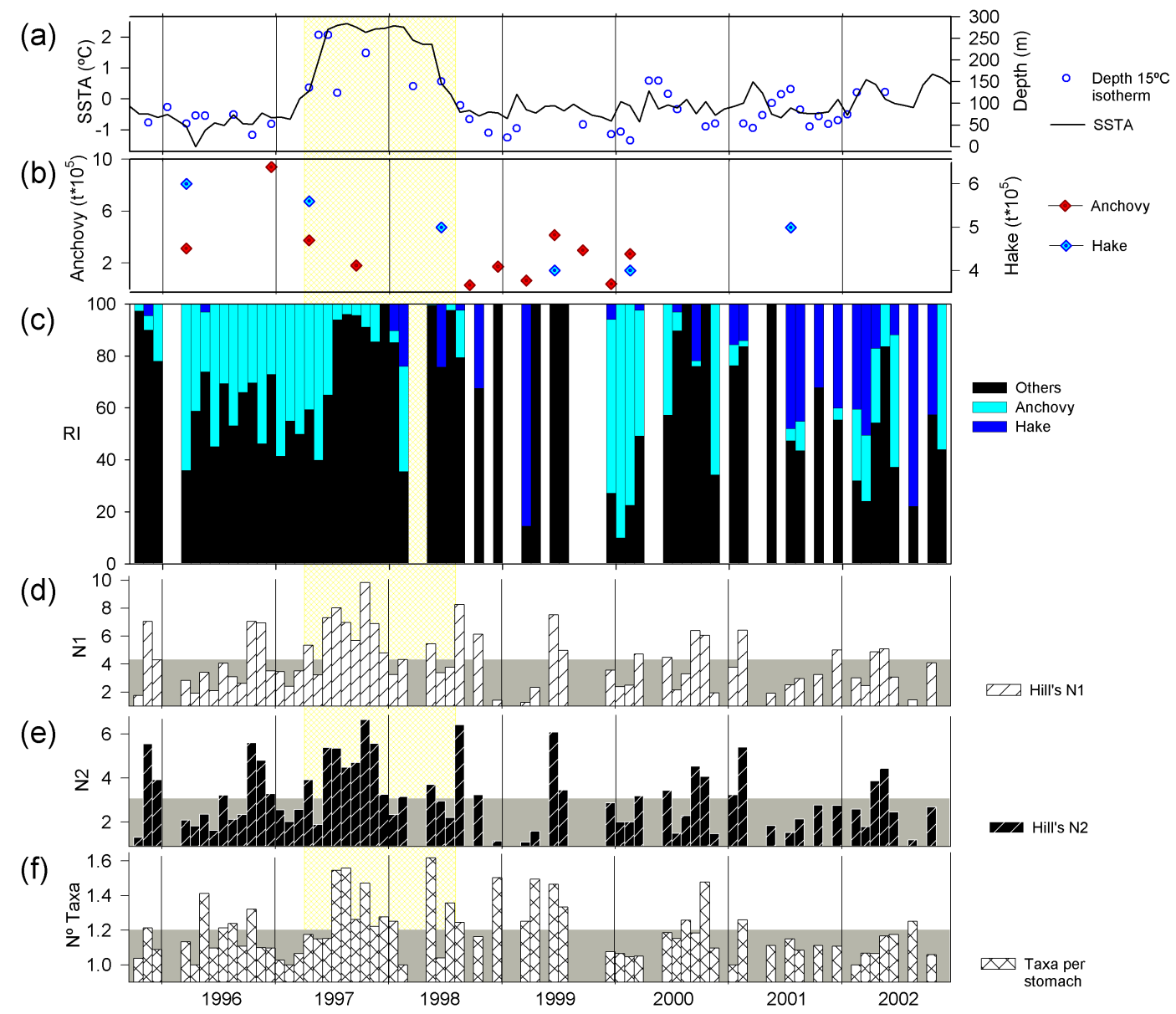

Fig. 4. Monthly variability (October 1995 to November 2002) of: (a) Marine physical signal, (b) Biomass estimations of main fish prey species, (c) Relative Importance (RI) of most abundant prey taxa in the diet of hake (251-450 mm TL size group), (d-e) Prey spectrum diversity (Hill's N1 and N2 numbers), and (f) Number of prey taxa per stomach. Period of highest SSTA is indicated with a shadowed grid. Months with less than 30 analysed stomachs were not considered.

N2 numbers; Hill, 1973) and mean number of prey taxa per stomach were used to explore changes in the diet associated with the physical and resources variability.

Monthly estimations of the Fullness Index $(F I)$ were performed:

$F I=100(S W / T W)$

where: $S W$ is the weight of the stomach content $(\mathrm{g})$ and $T W$ is the body weight of the hake (g).

Nonparametric confidence intervals of $F I$ were estimated by the t-student bootstrap resampling procedure (Efron, 1982).

\section{Results and discussion}

A total of 5563 stomachs were examined during the study period, $11.6 \%$ of them were empty. Overall, the most important prey species in the stomach content of the total sample were hake, anchovy (Engraulis ringens) and euphausids. Three size-related groups of hake were defined based on diet composition in the cluster analysis. Significant differences $(\mathrm{P}<0.05)$ in the diet spectrum between such groups were detected by the ANOSIM procedure. SIMPER analysis revealed that the diet of small hake was characterized by euphausids, whereas in large hake cannibalism predominated. Diet of hake sized between 251 and $450 \mathrm{~mm}$ TL is characterised by several taxa including anchovy, euphausids, cannibalism, pelagic shrimps (Hendrick and Estrada, 1996) (Pasiphaea americana, Plesionika spp.) and cephalopods (Loligo gahi, Dosidicus gigas) (Fig. 2).

Relative Importance (RI) of crustaceans in the diet of hake decreased with size while prey fishes showed the inverse tendency. Feeding strategy of hake shifts with size from a pelagic crustacean predator at small sizes, and a carnivorous generalist at intermediate sizes to a piscivorous, specialist which is strongly cannibalistic at large sizes (Espinoza, 2001) (Fig. 3). Most of the analysed hake specimens ranged between 251 and $450 \mathrm{~mm}$ TL, thus the subsequent monthly diet analyses are restricted to this size group.

SSTA off Paita increased during El Niño 1997-1998, while the $15^{\circ} \mathrm{C}$ isotherm deepened during the same period, 


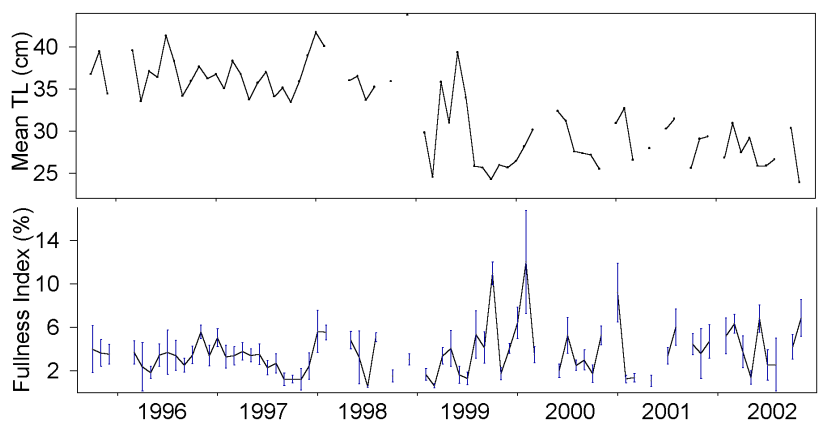

Fig. 5. Temporal changes of mean total length and fullness index $(F I)$ of hake. Error bars are $95 \%$ confidence intervals.

with a strong inverse relationship between both variables. With this consideration, in the subsequent analyses, the SSTA was used to explore the association between the physical habitat variability and the changes in the diet of hake (Fig. 4a).

Although anchovy is the dominant prey of the analysed size range of hake, the reduction of its availability during El Niño 1997-1998 (Chavez et al., 2003) (Fig. 4b) would not generate a resource or bottom-up control on the hake. Temporal variation of the importance of different prey in the diet of hake showed that the reduction of anchovy consumption generated a significant increase in the consumption of other prey, including shrimps, Sciaena deliciosa, myctophids and hake (Espinoza, 2000) (Fig. 4c). These evidences support the idea that hake is an opportunist predator of the HCE (Espinoza, 2001; Muck, 1989), so it would not be significantly affected by the reduction of anchovy.

An increase of prey spectrum diversity during the El Niño 1997-1998 event was observed at population level, as confirmed by the higher values of the RI index for the "others" prey category which grouped rare items (Fig. 4c) and by the increase of the diversity indices, considering both rare (N1 index) and common (N2 index) species (Figs. 4d and e). At individual level, an increment of prey taxa per stomach was observed during El Niño and persisting for two more years (Fig. 4f). In fact, tropical species (e.g. Bregmaceros bathymaster and Euphylax dovii) were recorded in the stomach contents during El Niño conditions, in concordance with the increase of fish and macrobenthic diversity observed during El Niño (Sanchez et al., 1985). This result supports the hypothesis of diversification (tropicalization) of the HCE during the warm phases of ENOS cycle (Arntz and Fahrbach, 1996). Predation has been proposed as a stabilizing factor of communities (Bax, 1998) and in this sense, hake seems to play such a role considering its opportunistic behaviour predating on several species.

The feeding activity (measured by the $F I$ ) seemed to be much more variable from one month to another in the period after El Niño 1997-1998, suggesting a higher heterogeneity in the food supply as a consequence of the warm event, a physiological impairment of hake or an effect of the abrupt reduction in mean total length of hake that occurred in 1999 (Fig. 5) and was postulated as a compensatory response to fishery pressure (Wosnitza-Mendo and Guevara, 2000). During the months of ocean warming, the FI presented very low values but they increased rapidly, exceeding the values observed before El Niño, although with higher variability, as indicated by the large confidence intervals (Fig. 5).

\section{Conclusions}

The increase in the prey spectrum diversity of the diet of hake (251-450 mm TL) at population and individual levels supported the hypothesis that the southern shift of tropical waters in the north of the HCE diversifies their food supply. Hake can be characterized as an opportunist predator according to the observed changes in its diet associated with El Niño events, thus it would not be significantly affected by population reductions of anchovy.

The feeding activity of hake had a higher variability in the period after El Niño 1997-1998, which could indicate high heterogeneity in the food supply as a consequence of impacts of the warm event on the biotic community structure of the HCE.

Overall, the diet of hake in the northern HCE exhibited transitory (such as the increased diversity of prey species in the stomach contents) and medium term (such as the increased variability in feeding activity) responses associated with El Niño, which should be incorporated both in population dynamics and food web analyses.

Acknowledgements. The Peruvian Marine Research Institute (IMARPE) supported this study and the presentation of the poster at the First Alexander von Humboldt International Conference on the El Niño phenomenon and its global impact.

Edited by: P. Fabian and J. L. Santos

Reviewed by: W. Arntz and another referee

\section{References}

Alheit, J. and Pitcher, T. J. (Eds): Hake: Fisheries, Ecology and Markets, Fish and Fisheries Series, 15, 487 pp., Chapman and Hall, London, 1995.

Arntz, W. and Fahrbach, E.: El Niño. Experimento climático de la naturaleza, Causas físicas y efectos biológicos, Fondo de Cultura Económica, México, 312 pp., 1996.

Bax, N. J.: The significance and prediction of predation in marine fisheries, ICES J. Mar. Sci., 55, 997-1030, 1998.

Chavez, F. P., Ryan, J., Lluch-Cota, S. E., and Ñiquen, M.: From anchovies to sardines and back: multidecadal change in the $\mathrm{Pa}$ cific Ocean, Science, 299, 217-221, 2003.

Clarke, K. L.: Non-parametric multivariate analyses of change in community structure, Austr. J. Ecol., 18, 117-143, 1993.

Clarke, K. L. and Green R. H.: Statistical design and analysis for a 'biological effects' study, Mar. Ecol. Prog. Ser., 46, 213-226, 1988. 
Efron, B.: The jackknife, the bootstrap and other resampling plans, SIAM CMNS-Natl. Sci. Found. Monogr., SIAM, Philadelphia, 38, 92 pp., 1982.

Espino, M.: El Niño 1997-98: su impacto sobre los recursos pesqueros y sus pesquerías, p. 112-129, Forum El Fenómeno El Niño 1997-98, Evolución, pronóstico y mitigación, Publicación Especial IMARPE, 150 p., 1999.

Espinoza, P.: Interacción trófica merluza - anchoveta, Existe realmente impacto por depredacion?, Bol. Inst. Mar Peru, 19 (1-2), 15-20, 2000.

Espinoza, P.: Alimentación de la merluza peruana y sus fluctuaciones en el tiempo, p. 50-54, Forum la merluza peruana (Merluccius gayi peruanus): biologia y pesquería, IMARPE, 120 p., 2001.

George, E. L. and Hadley, W. F.: Food and habitat partitioning between rock bass (Ambloplites rupestris) and smallmouth bass (Micropterus dolomieui) young of the year, Trans. Am. Fish. Soc., 108, 253-261, 1979.

Gutiérrez, M.: Estimados de biomasa hidroacústica de los cuatro principales recursos pelágicos en el mar peruano durante 19832000, Bol. Inst. Mar Perú, 19 (1-2), 139-156, 2000.

Hendrick, M. E. and Estrada, F. D.: Los camarones pelágicos del Pacífico mexicano, CONABIO, UNAM, 157 pp., 1996.

Hill, M. O.: Diversity and evenness: a unifying notation and its consequences, Ecology, 54 (2), 427-432, 1973.
Hyslop, E. J.: Stomach content analysis - a review of methods and their application, J. Fish Biol., 17, 411-429, 1980.

Konchina, Y.: The feeding niche of the hake, Merluccius gayi (Merlucciidae), and the jack mackerel, Trachurus symmetricus (Carangidae), in the trophic system of the Peruvian coastal upwelling, J. Ichth., 23 (2), 87-98, 1983.

Muck, P.: Major trends in the pelagic ecosystem off Peru and their implications for management, in: The Peruvian upwelling ecosystem: dynamics and interactions, edited by: Pauly, D., Muck, P., and Tsukayama, I., 336-403 (438 p.), 1989.

Paredes, C., Cardoso, F., and Tarazona J.: Distribución temporal de moluscos y crustáceos tropicales en la Provincia peruana y su relación con los eventos El Niño, Rev. Peru. Biol., 11( 2), 213218, 2004.

Sanchez, G., Vélez, J., and Chipollini, A.: Un pez panameño en aguas peruanas: Bregmaceros bathymaster durante El Niño 1982-83, Bol. Lima, 38, 92-96, 1985.

Ware, D. M.: Production characteristics of upwelling systems and the trophodynamic role of hake, in: Benguela trophic functioning, edited by: Payne, A., Brink, K. H., Mann, K. H., and Hilborn, R., S. Afr. J. Mar. Sci., 12, 501-513, 1992.

Wosnitza-Mendo, C. and Guevara, R.: Adaptive response of Peruvian hake to overfishing, NAGA, 23, 24-28, 2000. 